\section{JOURNAL OF THE SOUTH AFRICAN INSTITUTION OF CIVIL ENGINEERING}

Vol 58 No 3, September 2016, Pages 2-12, Paper 1337

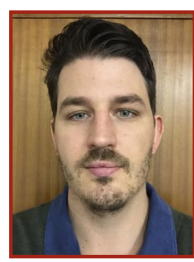

RYAN BRADLEY received his BSC (Eng) and MSC (Eng) from the University of the Witwatersrand He is currently a lecturer (and PhD candidate) in the School of Civil and Environmental. Engineering where he teaches structural analysis to engineering, architecture and construction management students. His main research interests are related to the analysis,

design and construction of unreinforced earth-masonry shells.

\section{Contact details:}

School of Civil and Environmental Engineering

University of the Witwatersrand

Private Bag 3

POWits, 2050

South Africa

T: +27117177127

E: ryan.bradley@wits.ac.za

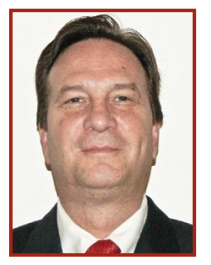

PROF MITCHELL GOHNERT (Pr Eng, FSAICE) graduated from Brigham Young University, USA with a BSc in Civil Engineering and a Masters of Engineering Management in 1985 and 1987 respectively. In 1995 he was awarded a PhD in Civil Engineering from the University of the Witwatersrand. He is registered as a Professional Engineer in South Africa and a Chartered Engineer in the United Kingdom. He is a full professor in structural engineering and was the Head of the School of Civil and Environmental Engineering at the University of the Witwatersrand at the time of writing this paper.

\section{Contact details:}

School of Civil and Environmental Engineering

University of the Witwatersrand

Private Bag 3

POWits, 2050

South Africa

T: +27117177125

E: mitchell.gohnert@wits.ac.za

\title{
Three lessons from the Mapungubwe shells
}

\author{
R A Bradley, M Gohnert
}

Shell structures show several unique structural attributes, which promote their use when material and economic efficiency is required. The principal advantage of shells is that forces are largely transferred through in-plane action (i.e. axial forces), with only limited bending and shear forces. This has endorsed the use of unreinforced shells which can been designed through numerous methodologies - i.e. thrust line analysis (O'Dwyer 1999), shell theory (Farshad 1977), finite element analysis (Ramm \& Mehlhorn 1991) and numerous physical modelling techniques - to ensure that only compressive stresses exist in the structure. Of specific discussion in this paper are the shells of the Mapungubwe Interpretation Centre, which are built exclusively from unreinforced earth tiles. Because the shells are unreinforced and earth tiles are susceptible to tension cracking, the shape of the structure and the construction practice are of paramount importance. Unfortunately, the Mapungubwe shells have cracked extensively, most notably at the openings. The causes of this cracking have been postulated in order to propose principles of good practice in designing and constructing unreinforced masonry shells. These guidelines were identified as follows: lips and eyebrows at shell openings should be avoided, shells should be unrestrained against expansion and contraction, and openings at the base should be of a catenary shape to match the flow path of compressive stress.

\section{INTRODUCTION}

The Mapungubwe Interpretation Centre is composed of multiple shell forms, which are striking and beautiful in appearance. The Interpretation Centre is located at the confluence of the Limpopo and Shashe rivers, where three countries meet - South Africa, Zimbabwe and Botswana - and is set deep into the bushveld, a local term used to describe a natural African bush environment. The magnificence of the shells (see Figure 1) earned them the 2009 World Building of the Year award at the World Architecture Festival - a fitting accolade for such magnificence (Mapungubwe Interpretation Centre 2009).

The form of the shell is based on a natural shape, comprising a series of catenary forms. The objective of the design is to achieve a purely compressive structure, without bending moments, shears and tensions. The material used in the construction of the shells is earthen tile, comprising seven layers for an average total thickness of $200 \mathrm{~mm}$. The construction method was patterned after the celebrated architect Rafael Guastavino, who was made famous by his unique style of timbrel vaulting (Milkovich 1992).

Most shell designs function primarily as membranes; in other words, the forces are carried in-plane, which are either compressive or tensile. The majority of shells also have boundary effects, such as bending moments or shears at the supports. To resist these types of forces, the shell must be able to resist both tensions and compressions throughout the shell, and bending moments and shears at the base. The Mapungubwe shells, however, are constructed of earth tiles and no steel is incorporated in the design. Thus, the shells are only capable of resisting a compressive force. This endeavour complicates the design substantially.

Earth tiles act similarly to masonry and concrete - the compressive strength is significantly stronger than the tensile strength. This property of earth materials is unforgiving to design errors, and the structure has a tendency to crack under small tensile forces. Thus, if the shape is not an accurate pure compressions form, the shell will crack, signifying a flaw in the design or construction. For this reason, unreinforced catenary shells are perfect forms to study, since any errors will be visually discernible. Earth shells tutor and communicate with the designer by the cracks that are formed.

Although the Mapungubwe shells have been designed by applying the latest technology of masonry shell theory (i.e. computational two-dimensional thrust line analysis and thrust-network analysis) as noted in Allen and Zalewski (2010), and Ramage et al (2010) - significant cracking is visible, indicating flaws in our understanding of design or construction practices. Many of the cracks, however, have occurred repeatedly in each of the shell forms. These crack patterns have been mapped out, 


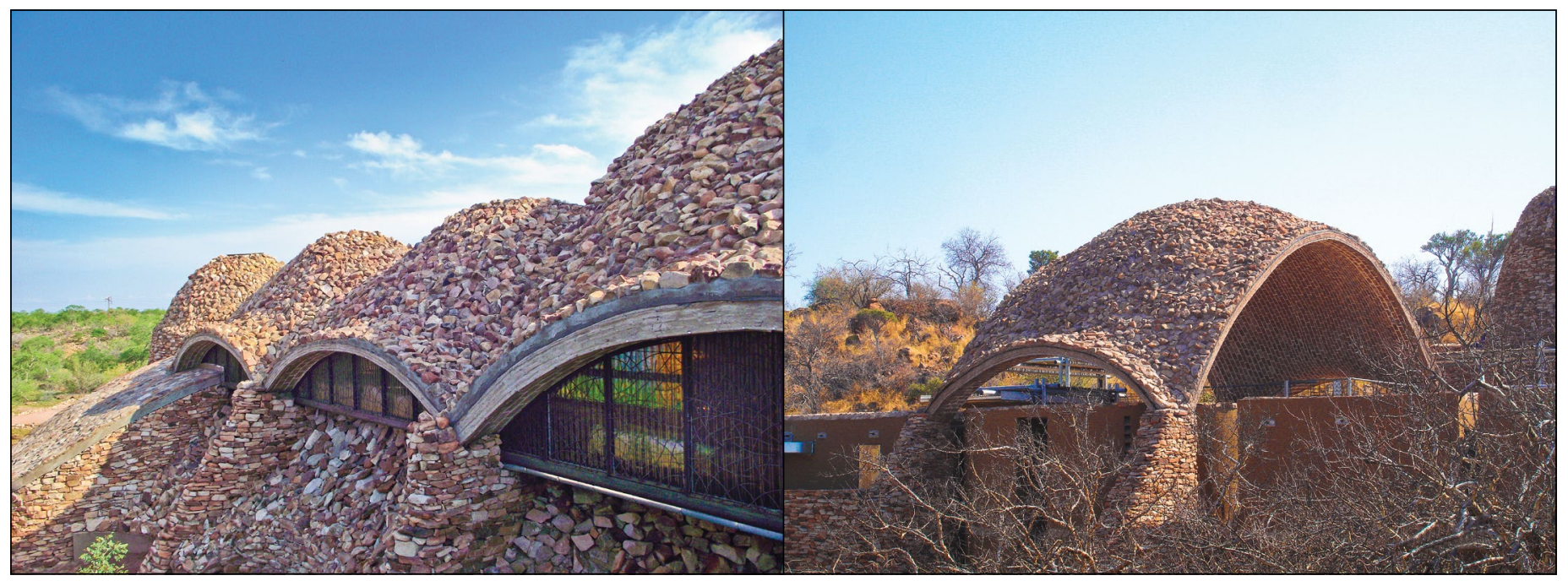

Figure 1 The Mapungubwe shells

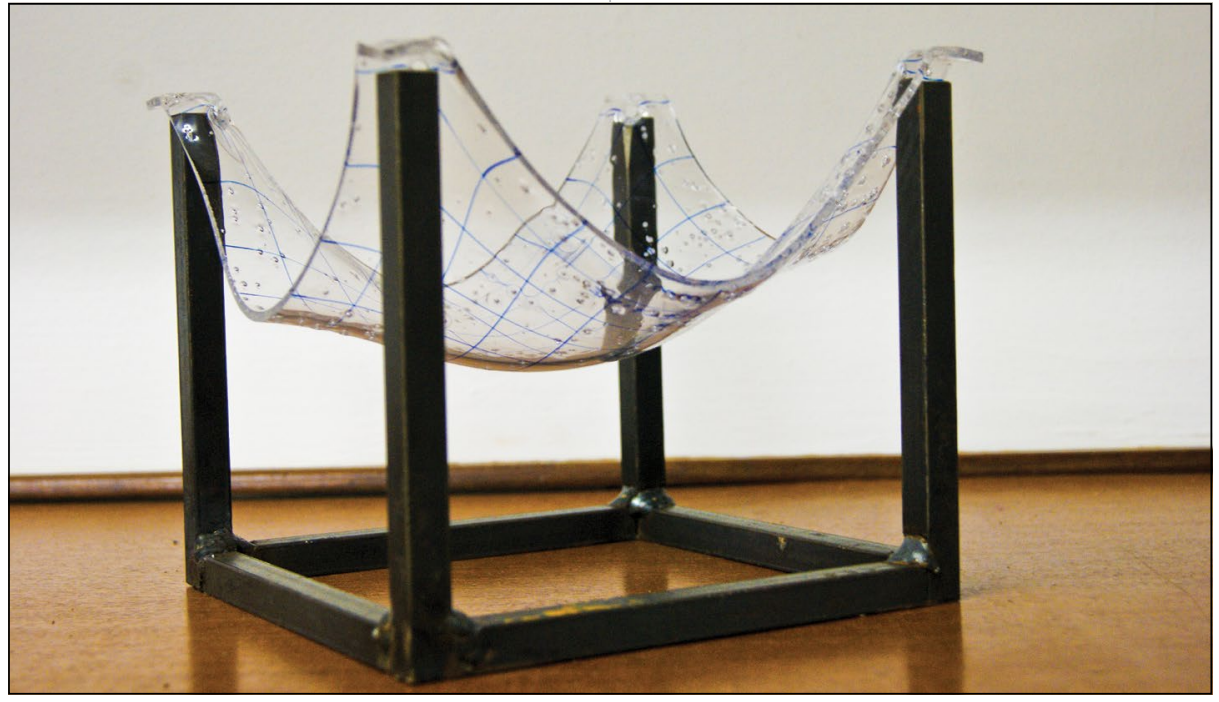

Figure 2 Hanging model using acrylic plates

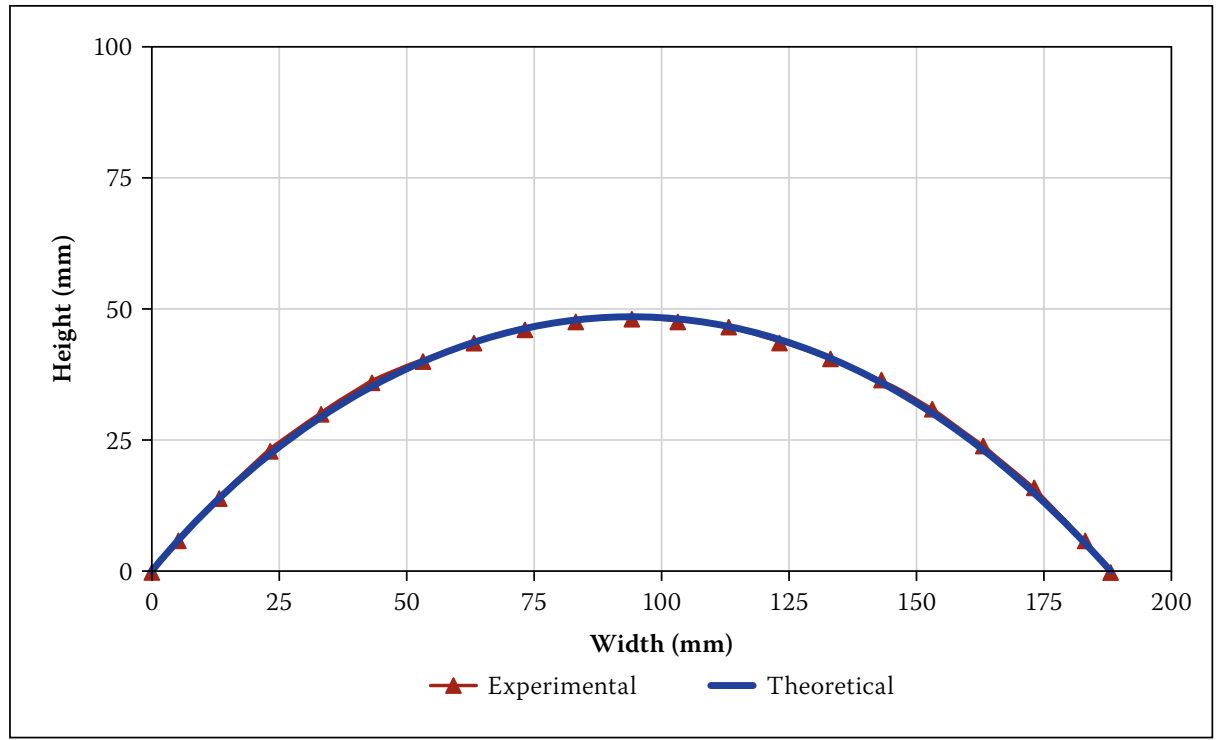

Figure 3 Experimental and theoretical catenary vault profiles

studied and analysed to determine the cause. Each is considered separately, accompanied by experimentation and analysis. The objective of this endeavour is to identify principles of good practice in the design and construction of masonry shells. such as in the Mapungubwe Interpretation Centre. Lips occur naturally in the classical handkerchief shape. This shape is made by supporting the corners of a handkerchief and allowing the cloth to drape naturally under gravity load. A catenary shell will form, but along the four edges of the handkerchief, lips appear, which are also sometimes referred to as eyebrows. The hanging cloth will be in pure tension, since fabric is unable to carry a bending moment, shear or compression. Subsequently, it may seem correct to assume that the lips are a necessary and an integral part of the structural resistance, and thus lips are sometimes incorporated into designs. Figure 2 is a hanging acrylic model of the handkerchief shape. Similar to cloth, the edges of the acrylic model droops, forming lips. The lips are, in fact, a redundant part of the structural shape. As observed in the Mapungubwe shells, if lips are incorporated in the design, the structure has a tendency to crack at the interface of the catenary shell and lip.

The Mapungubwe shell has significant cracking in the regions of the lips. The crack is located at the change in curvature, i.e. where the lip begins. It is mooted that cracks form because of the disparity in stress between the stressed and unstressed regions of the shell, i.e. between the catenary dome and the lips. It has been found that the lips carry only a minor proportion of the shell load, contrary to what was previously thought. The shape of the lip is also catenary, and is resistant to the downward deflection of the catenary dome. A shearing force is created at the interface, resulting in cracking, and often a separation of the two structural elements. To substantiate the claim, a handkerchief model was formed by heating a $200 \mathrm{~mm} \times 200 \mathrm{~mm} \times 3 \mathrm{~mm}$ acrylic sheet $\left[\right.$ Poly(methyl methacrylate)] to $150^{\circ} \mathrm{C}$. The sheet is attached to a frame, which only offers support in the corners, and is then 


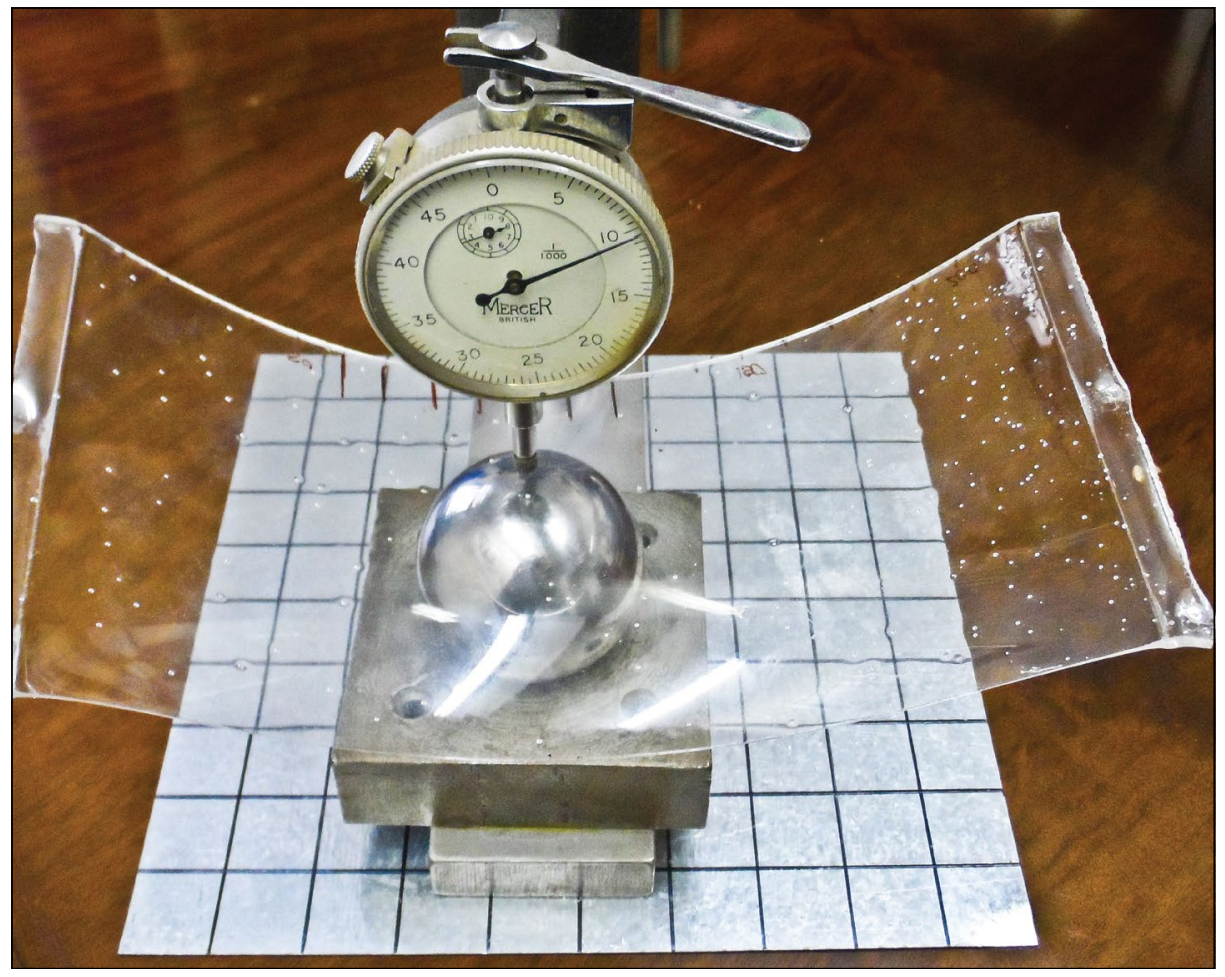

Figure 4 Thickness measurement apparatus heated by placing the sheet in an oven, with an even distribution of temperature. After about 2.5 hours, a shell forms, in the shape of a catenary vault (see Figure 2 ).

Initially a series of tests were conducted to assess the accuracy of the thermoforming process and testing apparatus. Two parameters were measured after the acrylic models had been removed from the oven and allowed to harden, namely the geometric profile and the thickness. The catenary shape, corresponding to an arch or vault, may be explained by considering a chain, which, when suspended from its two ends, will hang in pure tension. Catenary shapes were selected for the assessment of the modelling accuracy, primarily as tools to describe an ideal shape for a vault under self-weight, and because the theoretical profile and stresses are easily obtained through thrustline analysis procedures (Heyman 1995).

The experimental profile of the catenary shape is in good agreement with that of the theoretical profile, as shown in Figure 3.

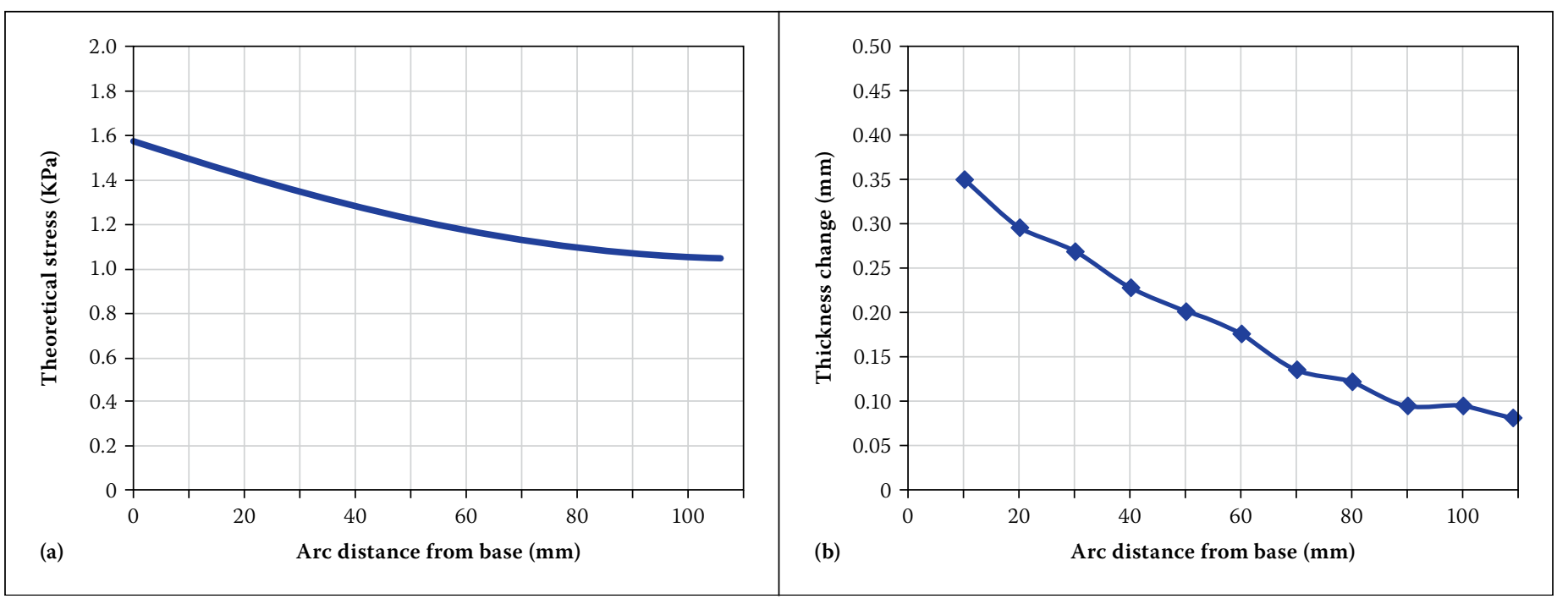

Figure 5 (a) Theoretical stress distribution, (b) Experimental: change in vault thickness

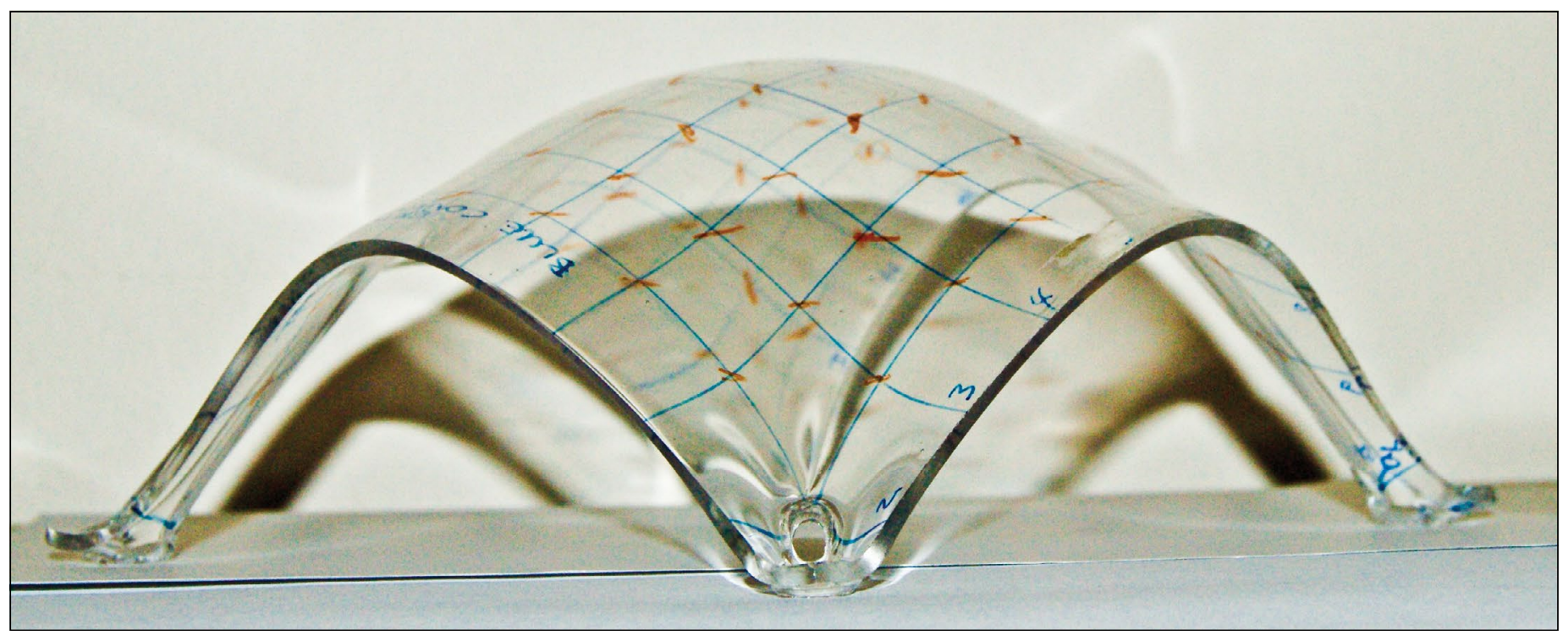

Figure 6 Acrylic model used to determine the flow of stress in a 'handkerchief' shape 
The profiles of the acrylic vaults, and those of the more complex catenary domes, were measured using a deflection gauge. In order to establish areas in which a stress disparity may be apparent, the material thickness was measured using a deflection gauge and steel ball to allow for variation in model curvature, as shown in Figure 4. The flow of stress within the model shell is proportional to the thickness of the shell - the greater the tension stress, the thinner the shell. This is demonstrated in Figure 5, which shows plots of the theoretical stress distribution along the arc length, from support to apex, and the measured change in thickness of the acrylic model. These initial tests demonstrated that the approach is adequate in describing the stress pattern within these structures.

At a temperature of $150^{\circ} \mathrm{C}$, the acrylic material is in a semi-fluid state, which causes the material to sag and form a natural structure, or rather a catenary dome (see Figure 6). The stress in the shell will not be even, but will flow and concentrate at the supports. The shell thickness was measured at 81 locations, and a contour colour scale denotes the thickness contraction in millimetres.

In Figure 7 the dark blue regions along the edges indicate very little change in thickness, and therefore minimal flow of stress. Measurements of the shell in the lip regions indicate that the thickness of the shell only contracts at most about $3 \%$. However, at the supports and towards the centre of the shell the stresses are far more substantial. The greatest stress occurs at the supports, as one would predict. Since the lips resist very little stress, this region is structurally redundant and may be removed without infringing on the structural capacity of the shell.

The boundary, which separates the catenary dome from the edge lips, is the inflection point (see Figure 6), which is easily discernible in the model. The flow of stress in the handkerchief shape is as illustrated in Figure 8. As observed, the stress flows around the free edges (lips) and converges at the supports. It is incorrect to assume that the lips provide structural resistance to loads. In Figure 2, the lip regions of the acrylic model are unstressed and hang limply, forming the so-called lips. These regions may be cut away or omitted without compromising or altering the structural capacity of the shell.

The method of hanging chains to determine the shape of a pure compression structure has been the architect/engineer's tool for centuries (Kurrer 2008). The technique requires that the chains extend

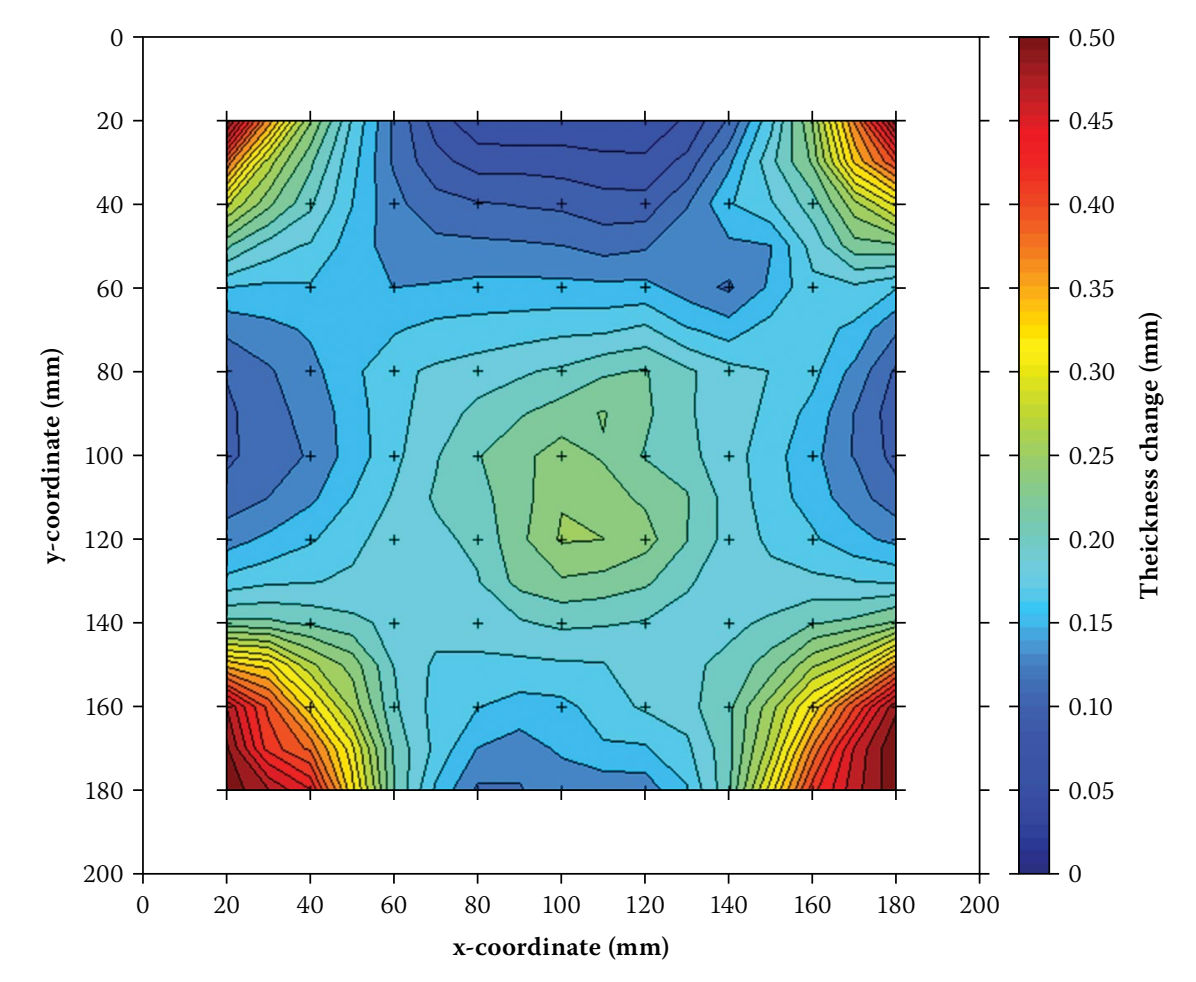

Figure 7 Contour plot of the stress pattern in the acrylic model

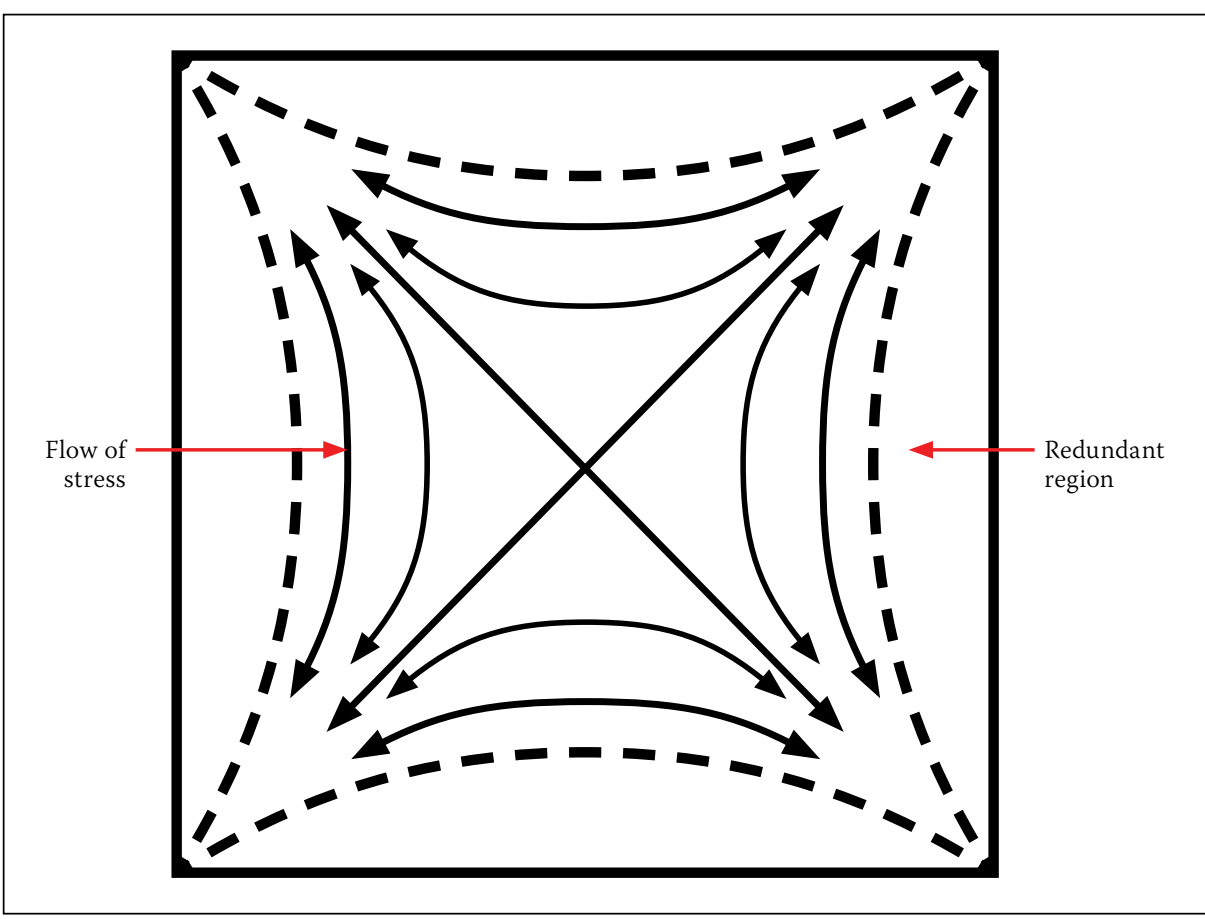

Figure 8 Redundant regions and flow of stress

radially from a central point, which is the apex of the dome. This method was used in preference to cloth models, since the weave interferes with the forming of the shape. For this reason, cross-chains, forming rings, are not placed in the model. In Figure 9 the shape is similar to the handkerchief, which is supported at the corners, and openings are located along the four edges. The technique of modelling with chains requires one to constantly adjust the length of the radial chains until a catenary dome is attained, i.e. when a smooth curve forms at the apex.
Never at any stage in the construction of the chain model did eyebrows or lips form along the edges - lips only appear in cloth models. If the lips of the acrylic model are cut away, the resulting shape is identical to the chain model. Both shapes exhibit similar characteristics - the openings along the edges are catenary and the edge of the openings lean into the shape; thus, a side view displays a catenary profile.

The disparity of stresses between the lips and the catenary structure is significant. The flow of stress within the 
catenary dome will cause the shell to deflect downwards. The lips, or eyebrows, do not carry the shell load (other than its own selfweight) and therefore the deflection of the lip will be significantly less; for this reason, cracking is often observed where the lips are attached to the catenary dome. The Mapungubwe shells are no exception - significant cracking was observed in the region of the lip's point of inflection, where the lips are attached to the catenary dome. The crack was repaired on several occasions, identified as a continuous white line at the interface in Figure 10.

The disparity of stresses at the inflection point is further substantiated by a linear finite element analysis. The analysis was conducted using FEM software LISA v7.6 (LISA). The spatial coordinates were physically measured from the acrylic model and used to create the finite element model (see Figure 11). For simplicity, a single quadrant was entered into the FEA software; this was then mirrored and rotated to achieve a full shell. A uniform gravitational load was applied to the structure to simulate the weight of the acrylic material. The properties of the FE model are given in Table 1. The corresponding major principal stress contour plots are shown in Figure 12. It should be noted that some localised bending was evident in the FE model due to the lack of "smoothness" of the input data. However, the overall principal stress pattern is strikingly similar to the acrylic model measurements, confirming the redundant nature of lips located along the free edges.

\section{LESSON 2: SHELLS SHOULD BE UNRESTRAINED AGAINST EXPANSION AND CONTRACTION}

Shell structures are like a living lung - the shell will expand and contract according to the thermal exposure. If the materials used in the construction of the shell have similar coefficients of thermal expansion, cracking should not occur (especially in thin shells which have a small thermal gradient through the thickness). The only critical region is usually at the supports, where the shell is most likely restrained - always in translation, but sometimes in rotation. Many shell structures include openings for doors and windows. Some shell structures, such as barrel vaults, are closed at the ends with vertical walls. These elements in the structure tend to be problematic and cause cracking if they restrain the thermal movement of the shell. In Figure 13 cracking in two window openings is discernible. The crack pattern is similar at the location of all of the windows at Mapungubwe, and is consistently at the

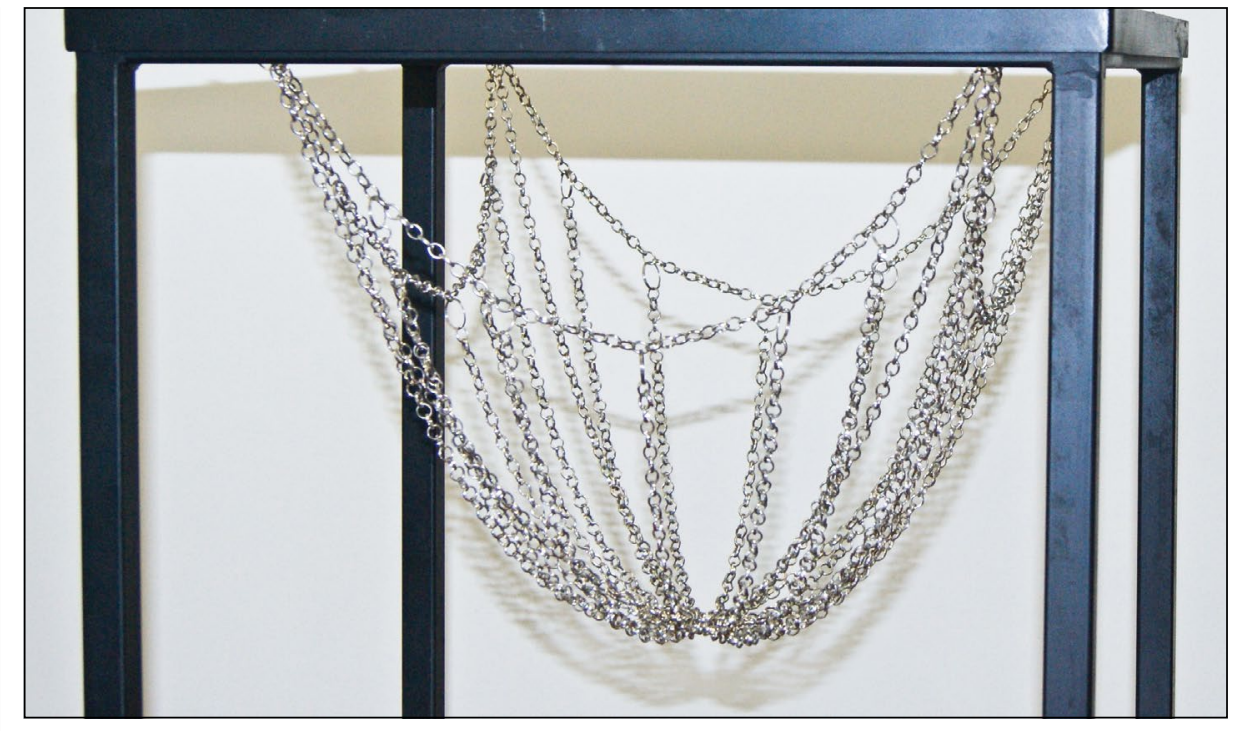

Figure 9 Chain model of a hanging structure supported at the corners

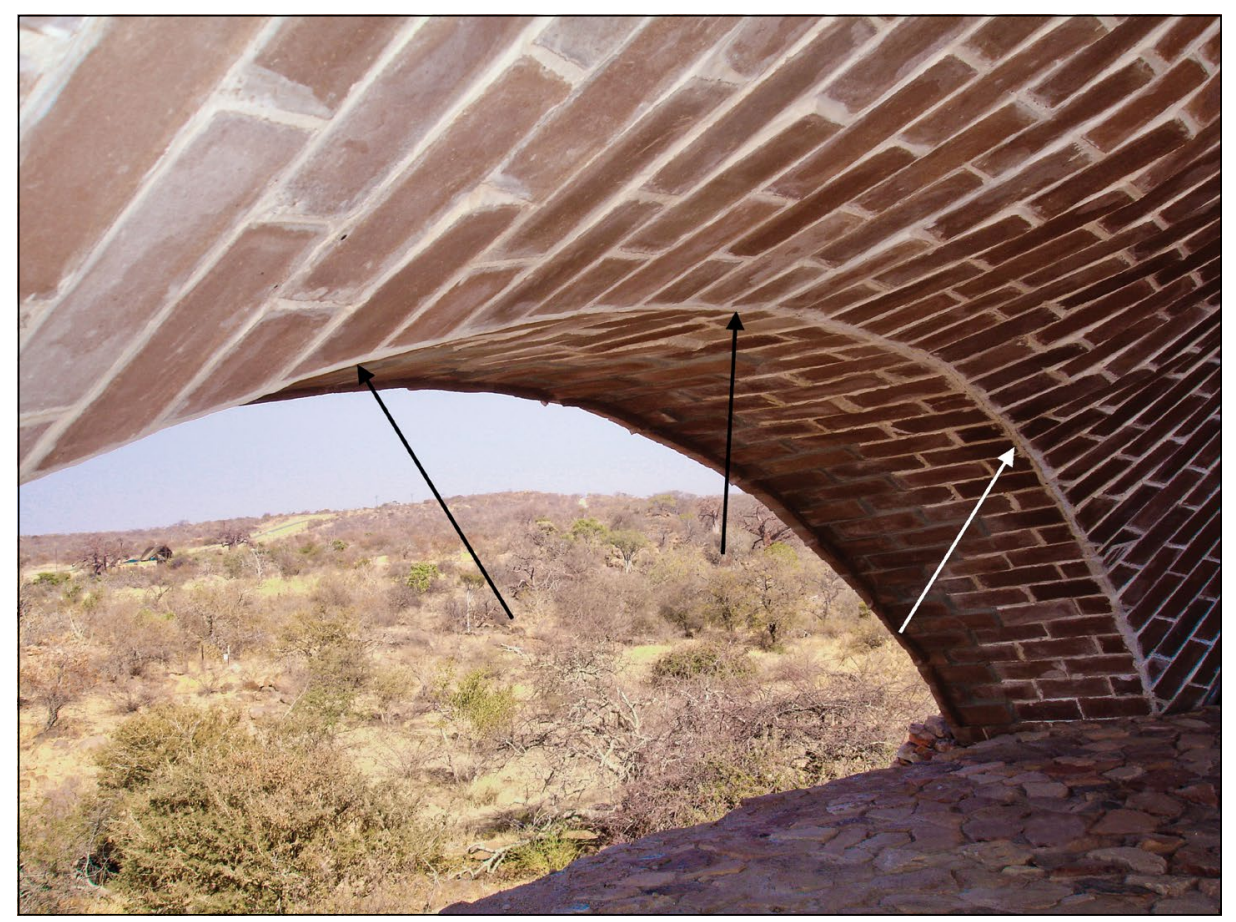

Figure 10 Repaired cracking near the inflection line of the lips

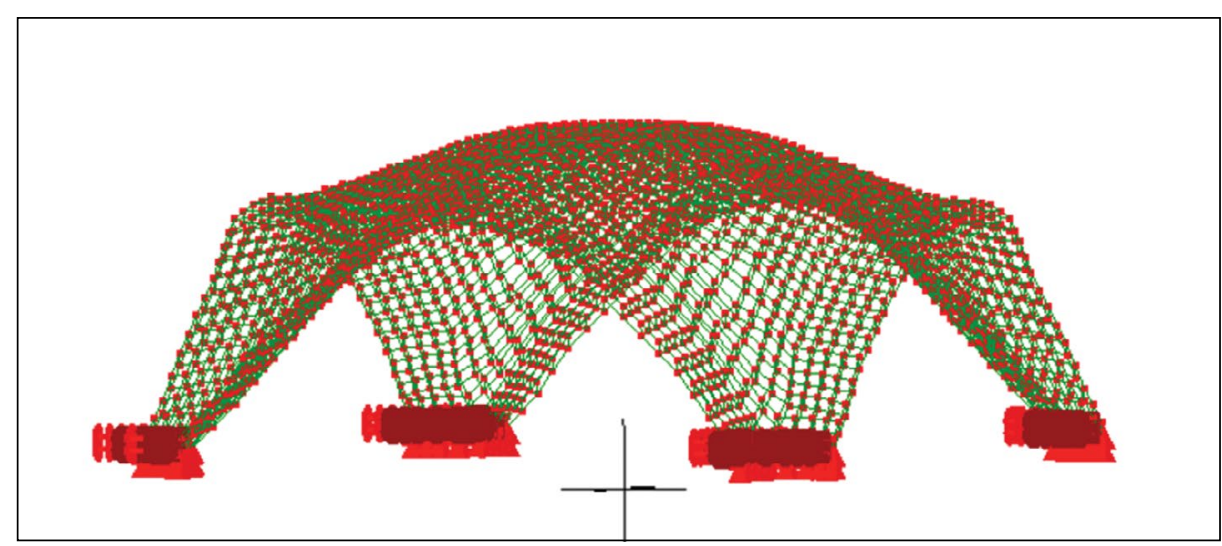

Figure 11 Finite element model of the catenary dome

Table 1 Finite element parameters

\begin{tabular}{|l|c|c|c|c|c|}
\hline \multicolumn{1}{|c|}{ Material } & $\begin{array}{c}\mathbf{E} \\
\left(\mathbf{N} / \mathbf{m}^{2}\right)\end{array}$ & $\mathbf{v}$ & $\begin{array}{c}\mathbf{t} \\
(\mathbf{m})\end{array}$ & $\begin{array}{c}\text { Density } \\
\left(\mathbf{k g} / \mathbf{m}^{\mathbf{3}}\right)\end{array}$ & Element \\
\hline Acrylic & $3.2 \times 10^{9}$ & 0.4 & 0.003 & 1167 & 8-node hexagonal \\
\hline
\end{tabular}




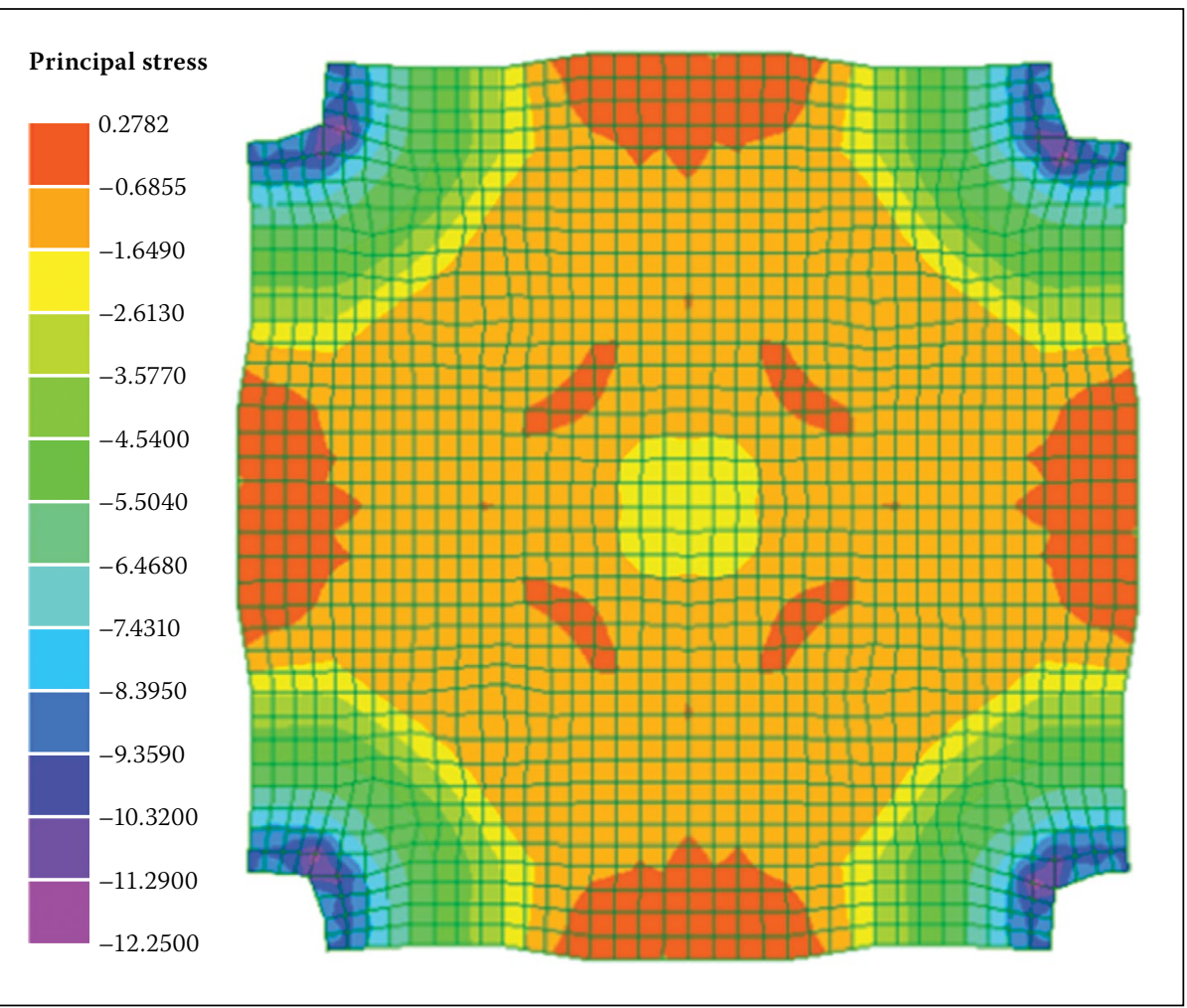

Figure 12 Major principal stress distribution in the finite element model

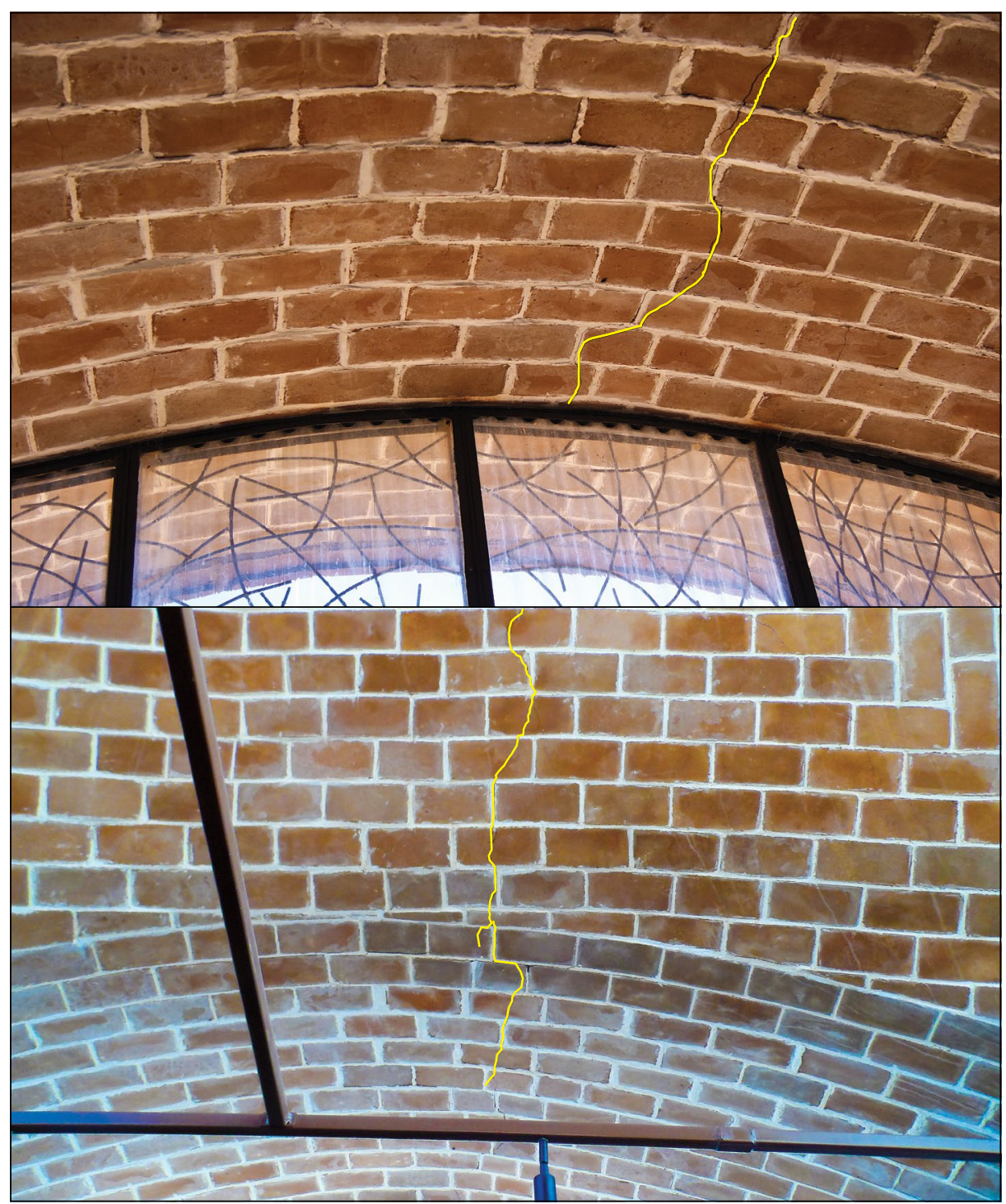

Figure 13 Cracking at the apex of two window openings at Mapungubwe (the cracks are traced in yellow for clarity)

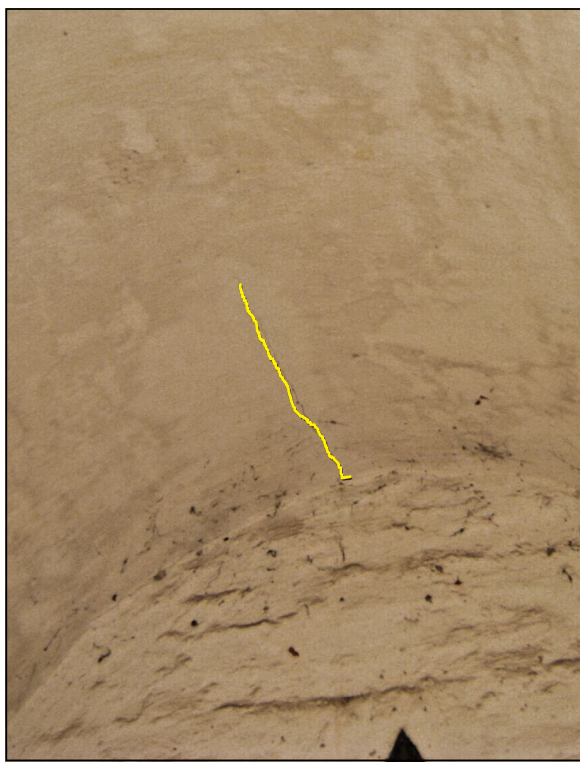

Figure 14 Cracking at high point in the Bapong shell above the end wall (the crack is traced in yellow for clarity)

highest point in the opening. The cause of cracking is the steel window frame, which is fastened solidly against the shell structure. In the region of the windows, the shell is unable to expand or contract, resulting in cracking. Another example is the Bapong shells, also located in South Africa (see Figure 14). Similar to the Mapungubwe shells, cracking in the Bapong shells also occurred at the high point where the end-wall meets the shell. The end-walls are connected solidly against the shell, preventing thermal expansion and contraction.

In Figure 15 a simple strain plot is proposed to illustrate the region of cracking observed in the masonry shells. The solid line (i.e. line 2) in Figure 15 represents compressive strains in the shell due to gravity loads. If the shell is evenly restrained against contraction, the shell will be subjected to tension strains (see line 1). The mid-point of the plot corresponds to the strains at the apex of the shell, and the left and right boundaries are the shell supports. If line 1 and line 2 are combined, the resulting total strains are illustrated by the dotted line, labelled as $1+2$. If the tensile strains are greater than the cracking strain of the shell material, the high point of the shell is the location where cracking is most likely to occur. The strains in Figure 15 correlate with what is observed above the window frames in the Mapungubwe shells and above the end-wall of the Bapong shells.

As mentioned previously, the temperature gradient in a thin shell is nearly constant. A change in temperature will cause the shell to expand or contract. Any restraint will thus cause cracking in the shell. The cracks observed at the high points in the openings of the Mapungubwe shells are where the 


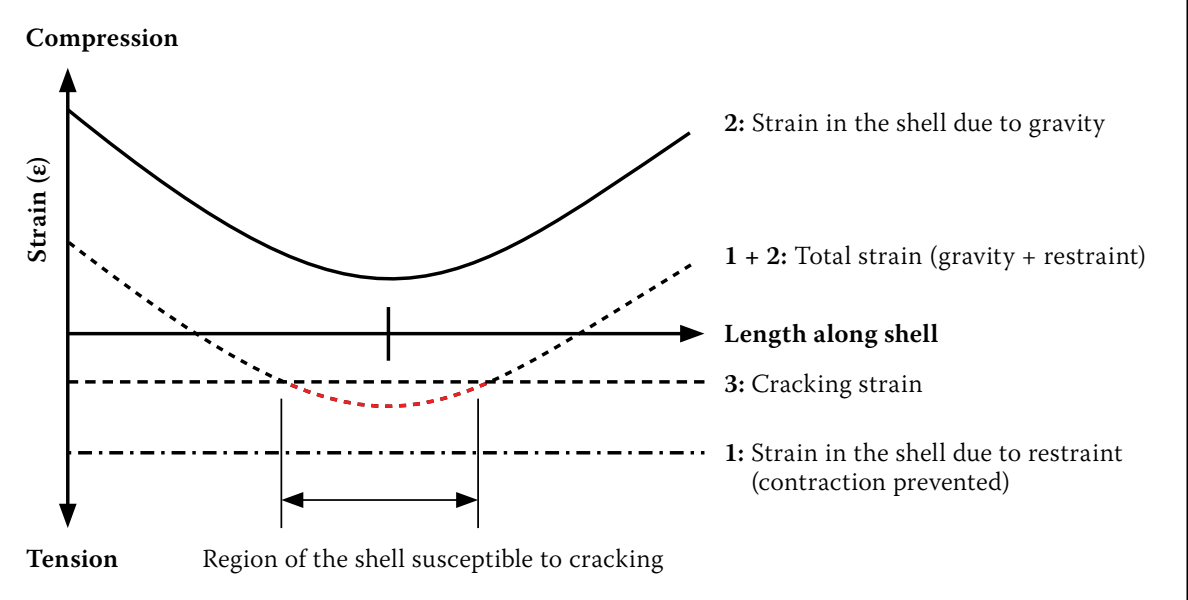

Figure 15 Strains in a shell due to gravity and restraint

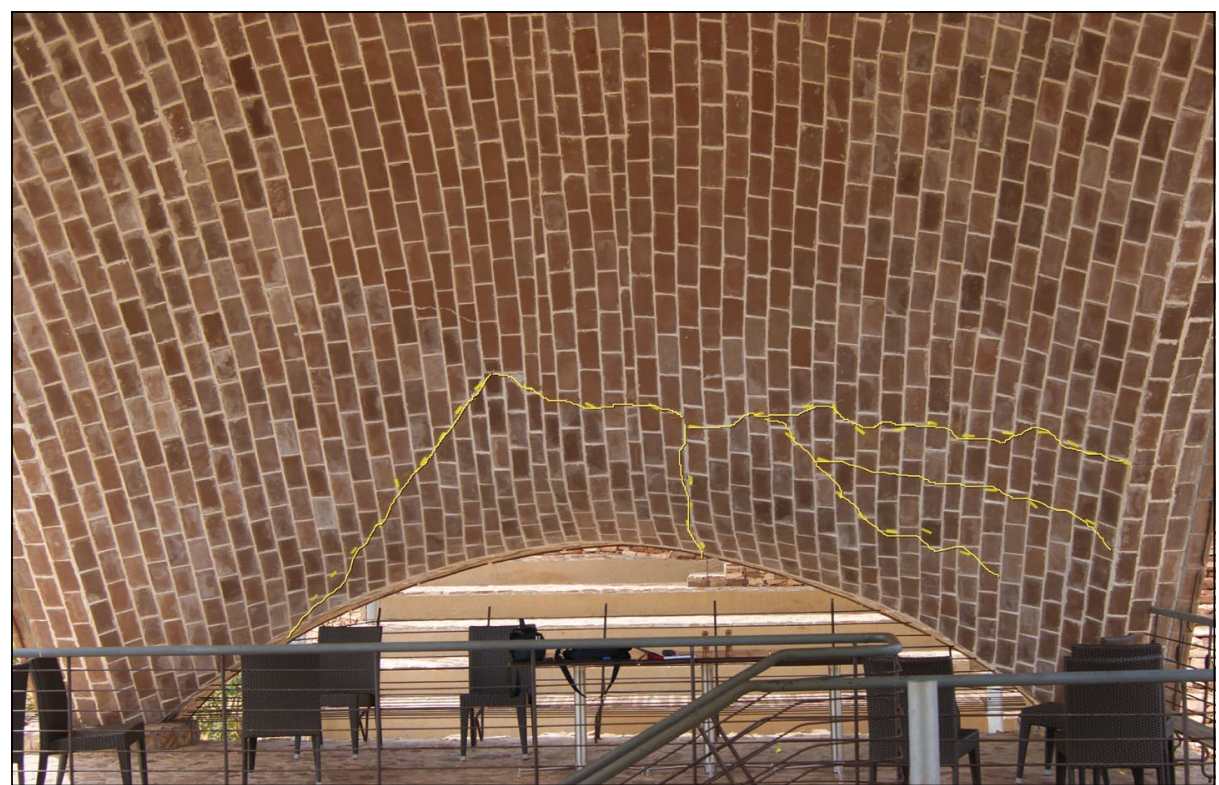

Figure 16 Cracking above a catenary opening at Mapungubwe (the crack is traced in yellow for clarity) potential for cracking is at the greatest, i.e. where the apex of the shell has minimal compressive strains due to gravity loads. To avoid cracking, an expansion joint should be placed above all window frames, doors and end-walls. The authors have used a $25 \mathrm{~mm}$ expansion joint in other structures, which has prevented comparable problems. A similar problem is also observed in shells that are constructed using formwork. However, the shell is only susceptible to this type of cracking after the final bricks have been laid. The contraction is due to shrinkage of the mortar, which is resisted by the rigid nature of the formwork. Thus, the formwork must be removed just after the initial set of the mortar to prevent cracking.

\section{LESSON 3: OPENINGS AT THE BASE OF SHELLS SHOULD BE CATENARY IN SHAPE (OF THE CORRECT PROPORTIONS)}

Often shell structures include large openings at the base. These openings are primarily incorporated for aesthetic and architectural purposes, i.e. access, lighting and ventilation. Openings at the base are featured in many of the Mapungubwe shells. However, their inclusion influences the nature and distribution of stresses in the structure, most significantly around the openings themselves.

Substantial cracking in the vicinity of an opening is observed in the large open vault at Mapungubwe. The cracks are visible just above the catenary-shaped opening, as shown in Figure 16. In essence, stresses will

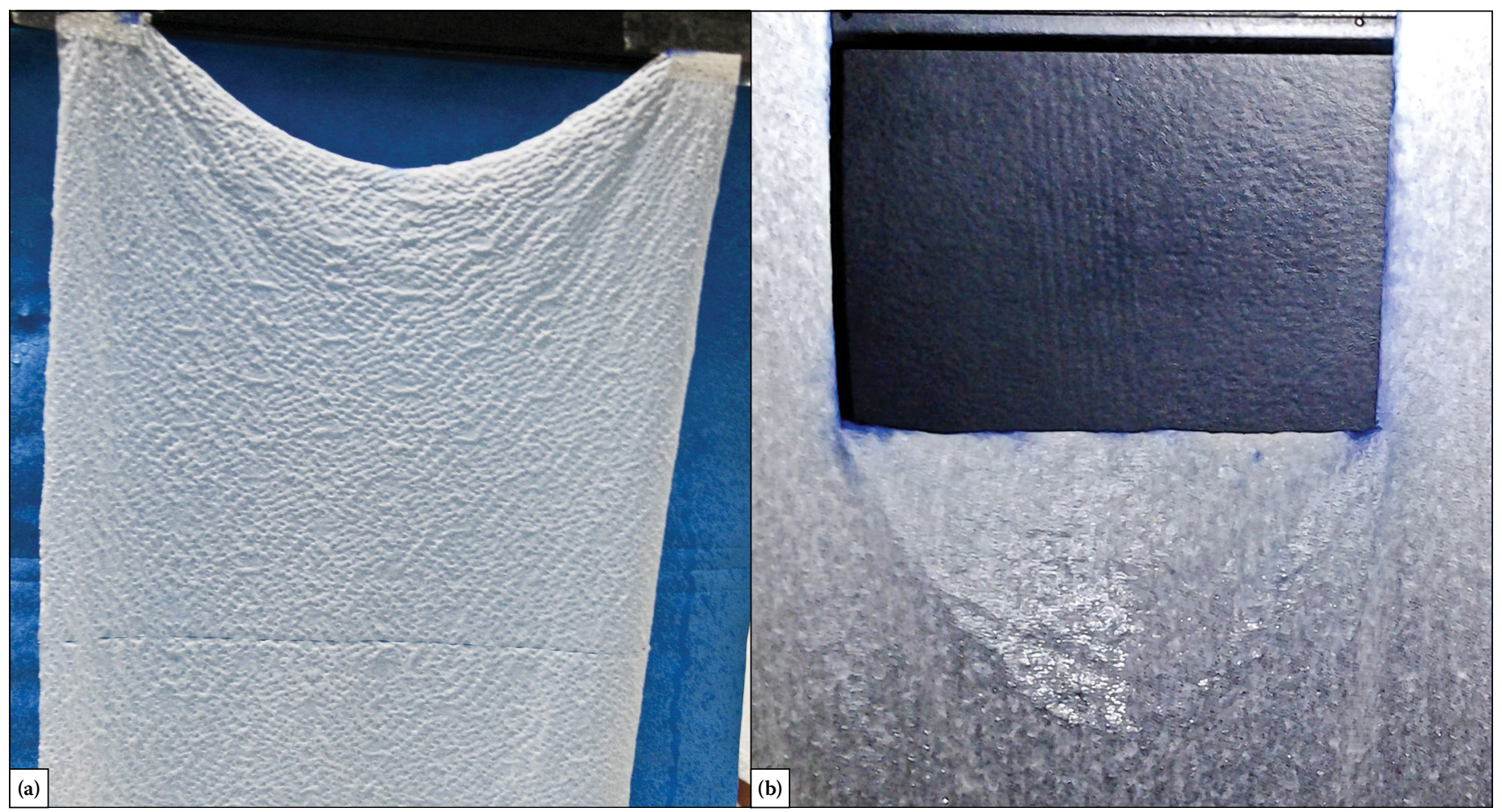

Figure 17 Paper models: (a) catenary opening, (b) rectangular opening 


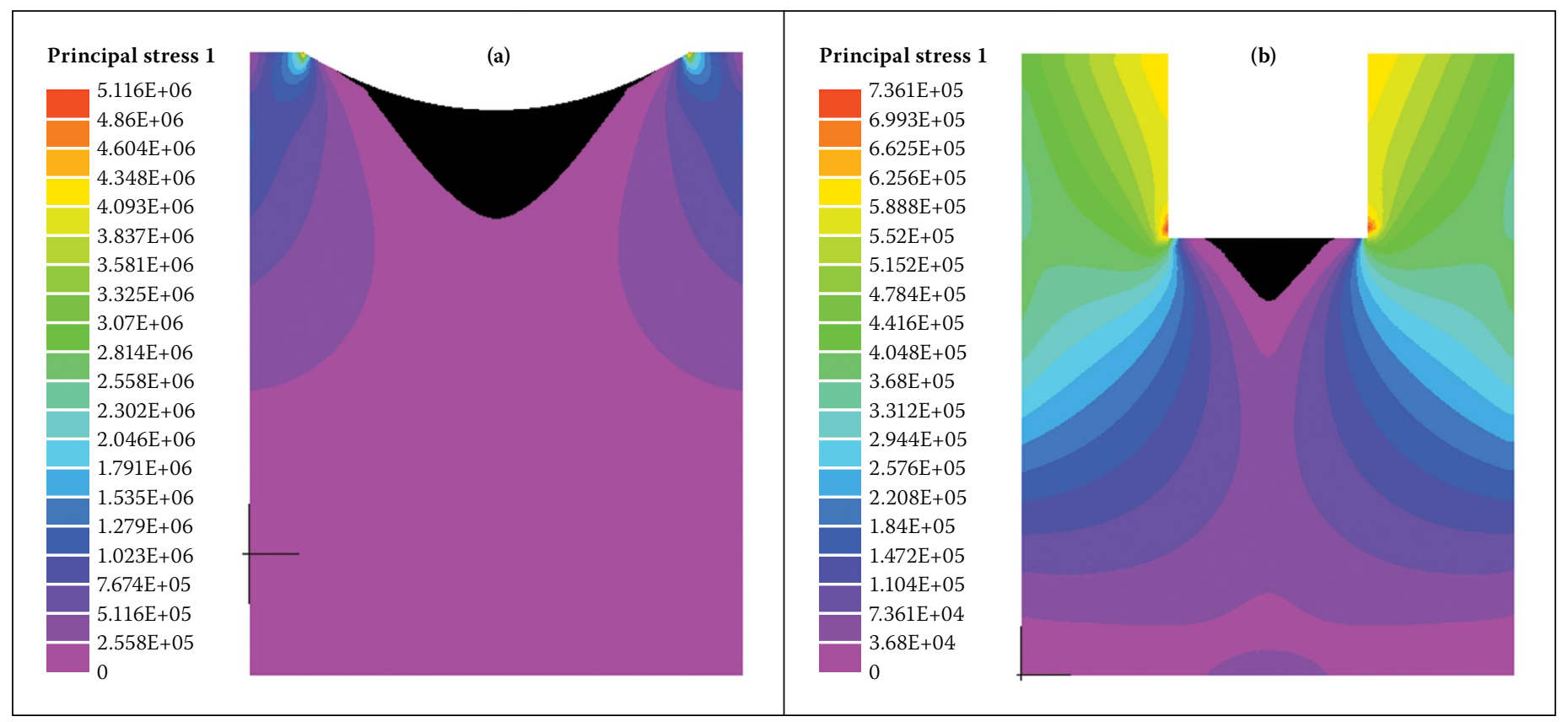

Figure 18 Finite element models: partial fixity - (a) catenary, (b) rectangular

flow to the supports in a predictable pattern, which is arched in nature. This flow pattern has been identified in many structural elements, such as beams and slabs, and is therefore not a new revelation. Typically, this arching is simplified with a triangular load dispersal pattern.

A series of simple tests were conducted to ascertain the reason why cracking occurred above the openings, which consistently happened at several locations in the Mapungubwe shells. The flow of stress was studied by observing the sagging patterns of water-absorbent paper. Openings were first cut into the paper and then the paper was hung vertically. The paper was then sprayed lightly with water to apply a uniform load and to allow the paper to distort, uninhibited by the material properties. These models are principally in tension (identified by taut paper), but localised compressive stress, or no stress, is also evident (and identified by sagging paper). Numerous tests were conducted on both rectangular and catenary openings to assess the flow of tensile stress around the openings. Two of these models, and the corresponding sag zones, are shown in Figure 17. As observed, the stresses follow a catenary-shaped path to the supports.

Finite element (FE) models were also produced to substantiate the trends observed in the paper models. Triangular and quadrilateral elements were adopted in the study. A uniform gravity load, comparable boundary conditions (only vertical restraint was provided at the nodes) and material isotropy were applied to the FE model to simulate the paper models. The FE parameters for these models are given in Table 2 . The results of two of these analyses are shown in Figure 18. The zones marked in black, observed directly

Table 2 Finite element parameters for models with openings

\begin{tabular}{|l|c|c|c|c|c|c|}
\hline \multicolumn{1}{|c|}{ Model } & $\begin{array}{c}\mathbf{E} \\
\left(\mathbf{N} / \mathbf{m}^{2}\right)\end{array}$ & $\mathbf{v}$ & $\begin{array}{c}\mathbf{t} \\
(\mathbf{m})\end{array}$ & $\begin{array}{c}\text { Density } \\
\left(\mathbf{k g} / \mathbf{m}^{3}\right)\end{array}$ & $\begin{array}{c}\text { Span/ } \\
\text { Length } \\
(\mathbf{m})\end{array}$ & $\begin{array}{c}\text { Width } \\
(\mathbf{m})\end{array}$ \\
\hline Plate & $1.0 \times 10^{8}$ & 0.20 & 0.01 & 1000 & 0.30 & 0.26 \\
\hline Vault & $3.5 \times 10^{9}$ & 0.15 & 0.20 & 1950 & 6.0 & 3.2 \\
\hline
\end{tabular}

(a)

\begin{tabular}{ll} 
Principal stress 1 \\
& $3 \mathrm{E}+06$ \\
$2.85 \mathrm{E}+06$ \\
$2.7 \mathrm{E}+06$ \\
$2.55 \mathrm{E}+06$ \\
$2.4 \mathrm{E}+06$ \\
$2.25 \mathrm{E}+06$ \\
$2.1 \mathrm{E}+06$ \\
$1.95 \mathrm{E}+06$ \\
$1.8 \mathrm{E}+06$ \\
$1.65 \mathrm{E}+06$ \\
$1.5 \mathrm{E}+06$ \\
$1.35 \mathrm{E}+06$ \\
$1.2 \mathrm{E}+06$ \\
$1.05 \mathrm{E}+06$ \\
$9 \mathrm{E}+05$ \\
$7.5 \mathrm{E}+05$ \\
$6 \mathrm{E}+05$ \\
$4.5 \mathrm{E}+05$ \\
\hline $3 \mathrm{E}+05$ \\
$1.5 \mathrm{E}+05$ \\
0 \\
\hline
\end{tabular}

(b)

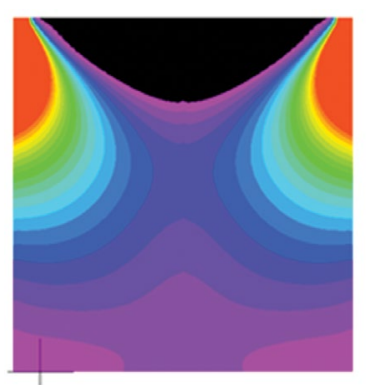

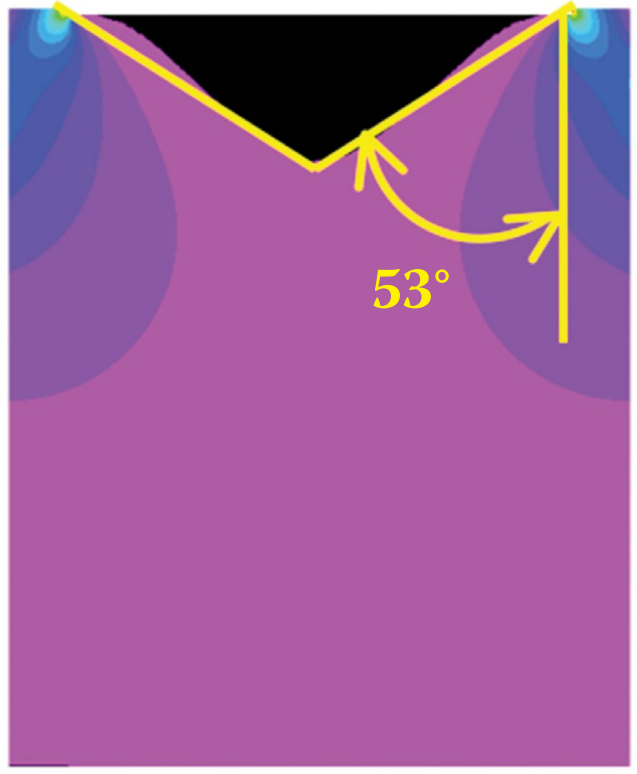
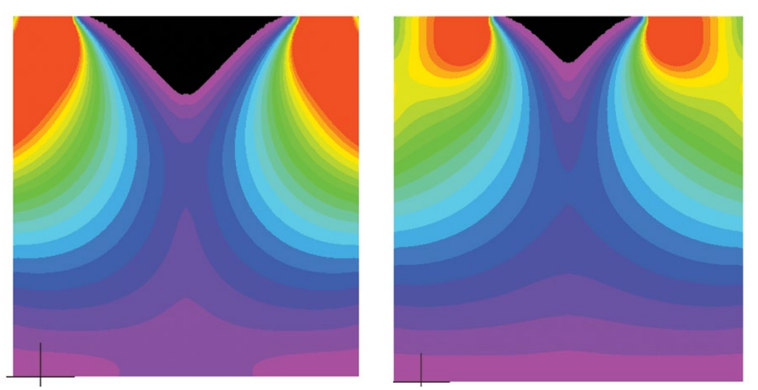

Figure 19 (a) Finite element model with narrow supports at ends, (b) Finite element model with different support widths: partial fixity 
Principal stress
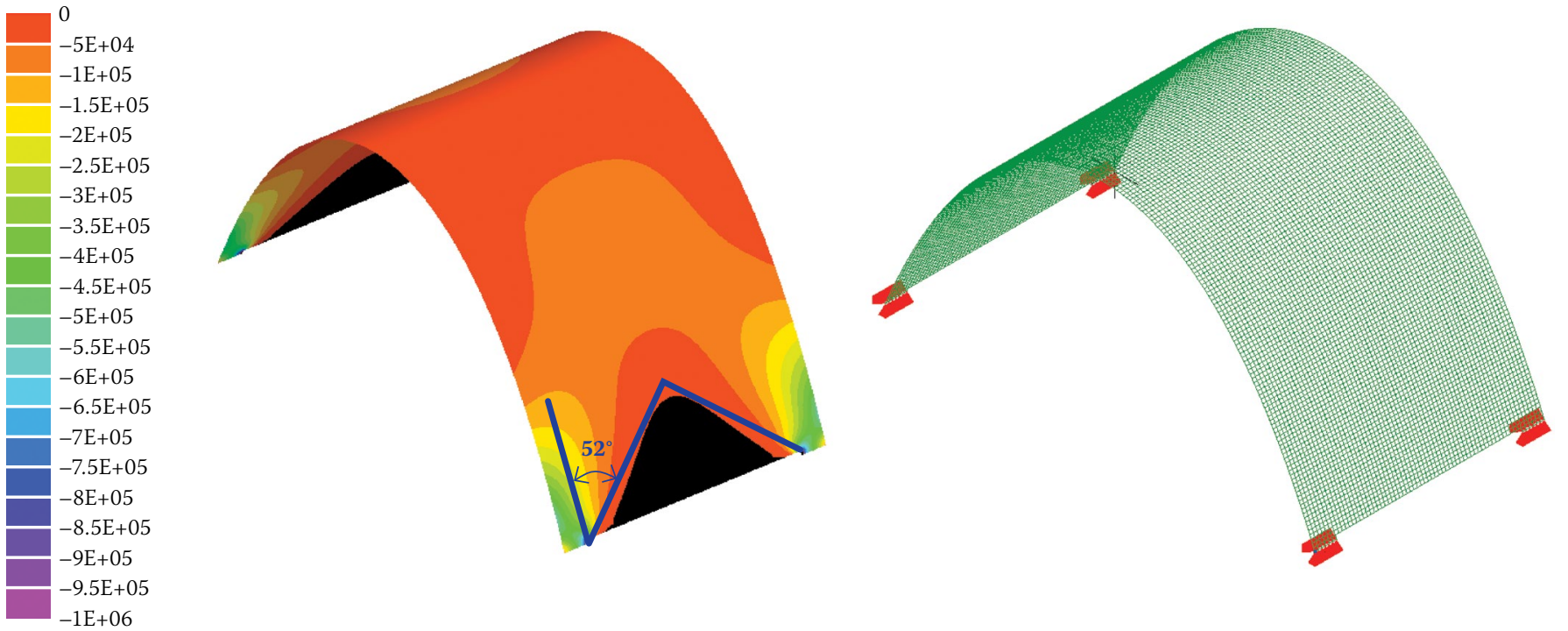

Figure 20 Finite element model of a catenary vault with narrow supports at both ends at base

below the openings, indicate compressive stress. Consequently, tensile stress must flow around this 'dead' zone to the supports.

It was apparent from the numerous paper model tests, and the corresponding finite element analyses, that a large sag zone was detected when rectangular and catenary openings were examined. The extent and depth of these zones varied noticeably with changes in opening height and width. A striking similarity was observed when comparing the paper and FE studies with the crack patterns above the catenary openings in the Mapungubwe shells. It should, however, be noted that a compression zone formed under all opening geometries due to the assumed support conditions, i.e. vertical restraint only.
To better understand the nature of these 'dead' zones, a stress flow study was undertaken on a plate configuration without an opening, just supported at either end of the FE model (see Figure 19a). If a triangle is inscribed on the plot, the angle measured from the triangle diagonally to the vertical is approximately $53^{\circ}$. This concept was further extended to a single-curvature catenary vault, primarily in compression (see Figure 20). Despite switching to a compression stress study (the paper models are tension flow studies), the flow of stress was found to be similar to the tension studies; the compressive stresses flow to the supports forming a catenary arch and the dead zone is of similar proportions. In this model, the inscribed triangle forms an angle with the vertical of approximately $52^{\circ}$. The flow of stress to the supports is therefore similar in planar and curved configurations, as well as tension and compression studies. If the support width of the plate shown in Figure 19a is increased (or decreased) the angle increases above $53^{\circ}$, resulting in a smaller compression zone. Consequently, the angle of $52^{\circ}-53^{\circ}$ defines the lower limit for the adopted configurations and boundary conditions.

Three illustrations corresponding to different support widths are shown in Figure 19b. For a very narrow support width, the compression zone looks strikingly similar to the shape of a catenary. However, for broader support widths the dead zone resembles a triangle. Thus, the extent of fixity at the supports alters the shape of the

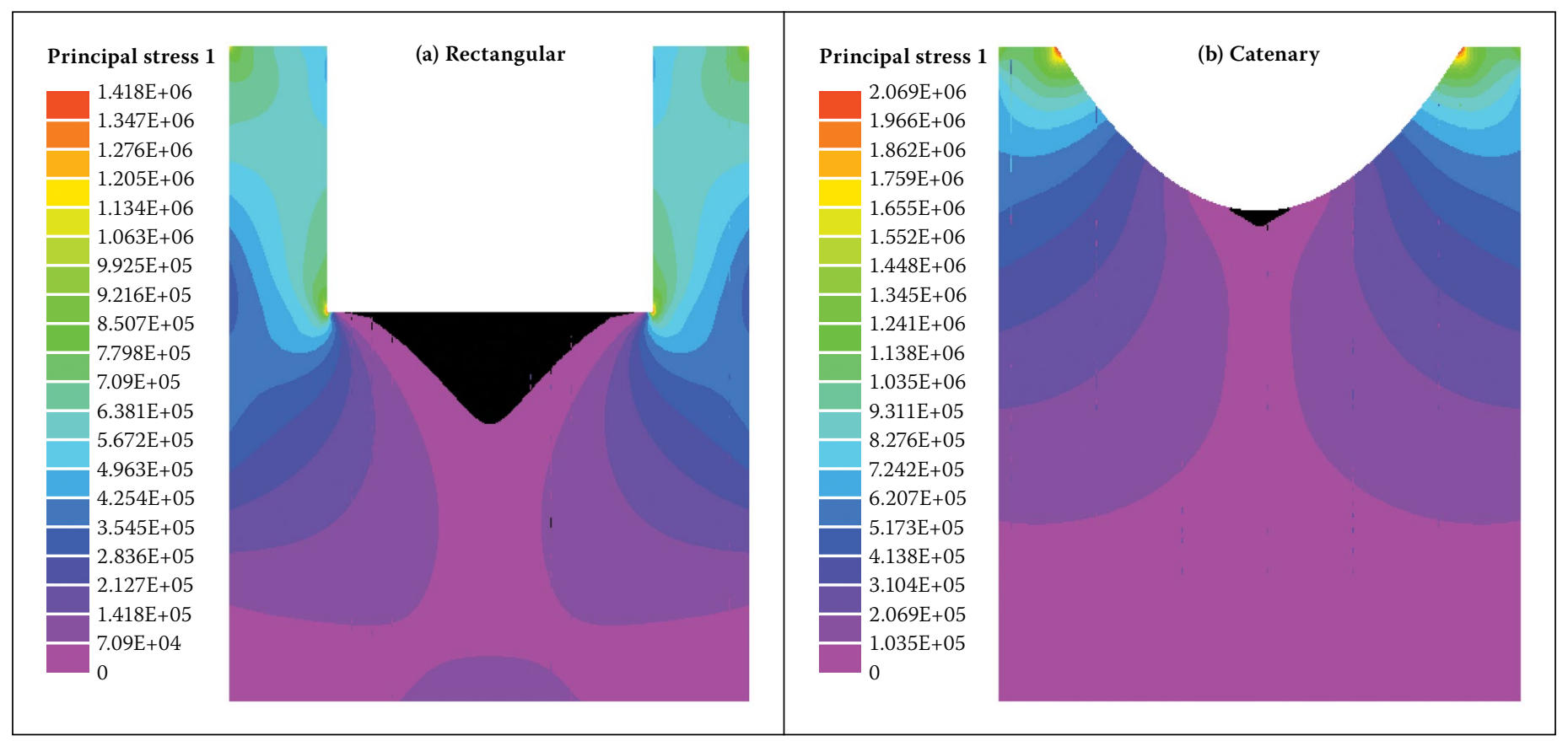

Figure 21 Finite element models: pinned supports - (a) rectangular, (b) catenary 
dead zone. It is common to assume a triangular load above an opening, and therefore this practice is consistent with our findings.

The extent of the compression zone decreases noticeably when lateral support is added to the base of the finite element models. (These support conditions most likely match the actual situation more closely). The major principle stress plots for a catenary and a rectangular opening, assuming pinned supports, are shown in Figure 21. It is apparent that a relatively large compression zone arises below the rectangular opening, when compared with that for the catenary opening (for which the zone has decreased substantially). This result demonstrates the advantage associated with a suitably proportioned catenary opening.

Referring back to the Mapungubwe shells (see Figure 22), a postulate for the observed cracking is due to the incorrect proportioning of the opening. Although the shell was designed using well understood techniques (i.e. two-dimensional graphic statics), it was built free-hand using reusable guide work (instead of continuous formwork) to save costs. This approach, however, has resulted in a degree of inconsistency in the constructions as shown in Figure 22(a)(b)(c) - kinks (or undulations), particularly in the upper extent of the shell, are evident. The shell is relatively thick and has a layer of stones on the outer face as an architectural feature. It appears, due to the lack of any cracking in the upper section of the shell, that this additional compressive load has sufficiently countered any localised bending (or tensions) associated with the sudden changes in geometry. In the lower sections, shape deviations at the base may have caused tension cracking above the opening. However, the crack pattern resembles a catenary curve, and the proportions match the FE and paper studies for partial fixity.

It should be noted that the Mapungubwe vaults are more complex than those modelled in the present study. However, a great deal of similarity was observed when comparing the crack patterns in the shell to the models (paper models and FE analysis). This leads to the deduction that the shape and proportions of the openings in masonry shells are vital to prevent tension zones and cracking along the interface of the catenary stress pattern.

\section{CONCLUSIONS}

A series of simple physical models and finite element analyses were conducted to examine the causes of cracking in the shell structures at the Mapungubwe Interpretation Centre. Many of the cracks have occurred

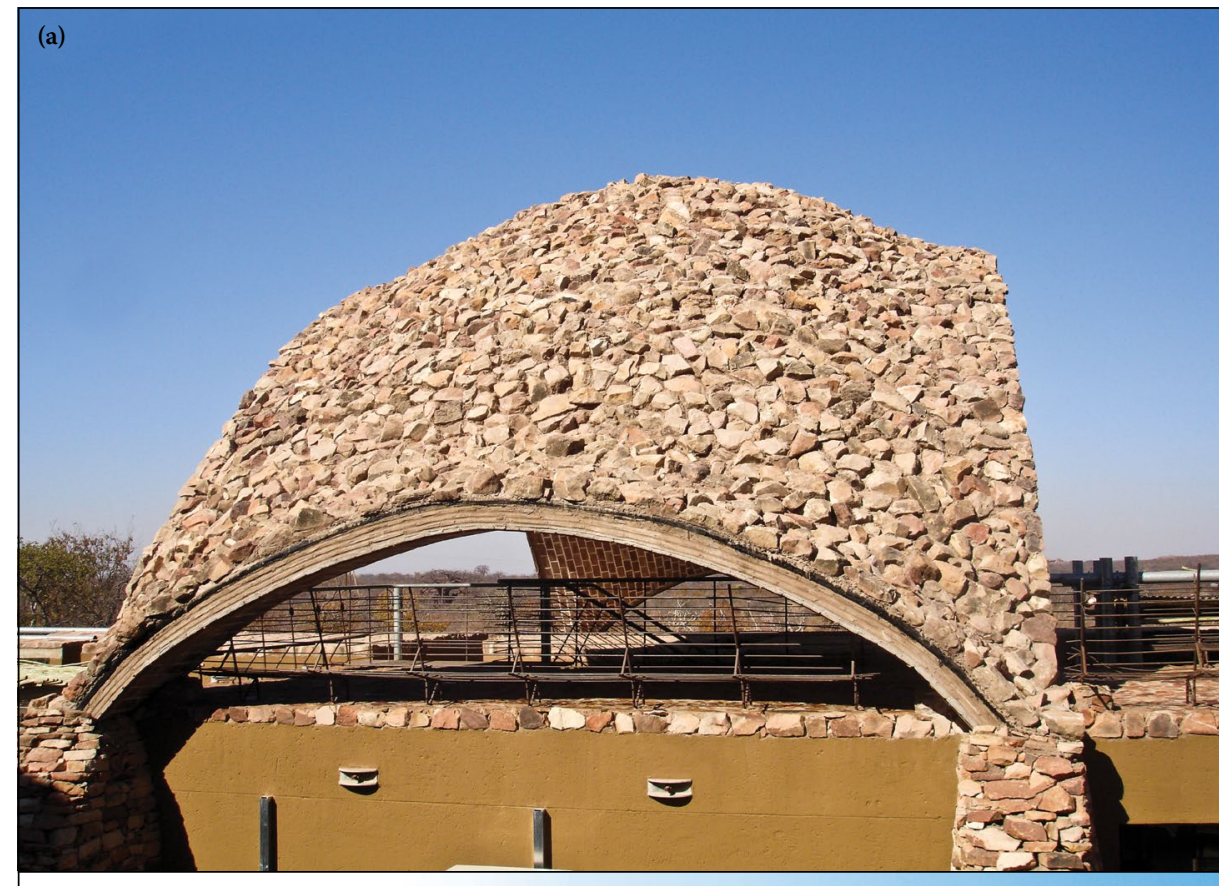

(b)

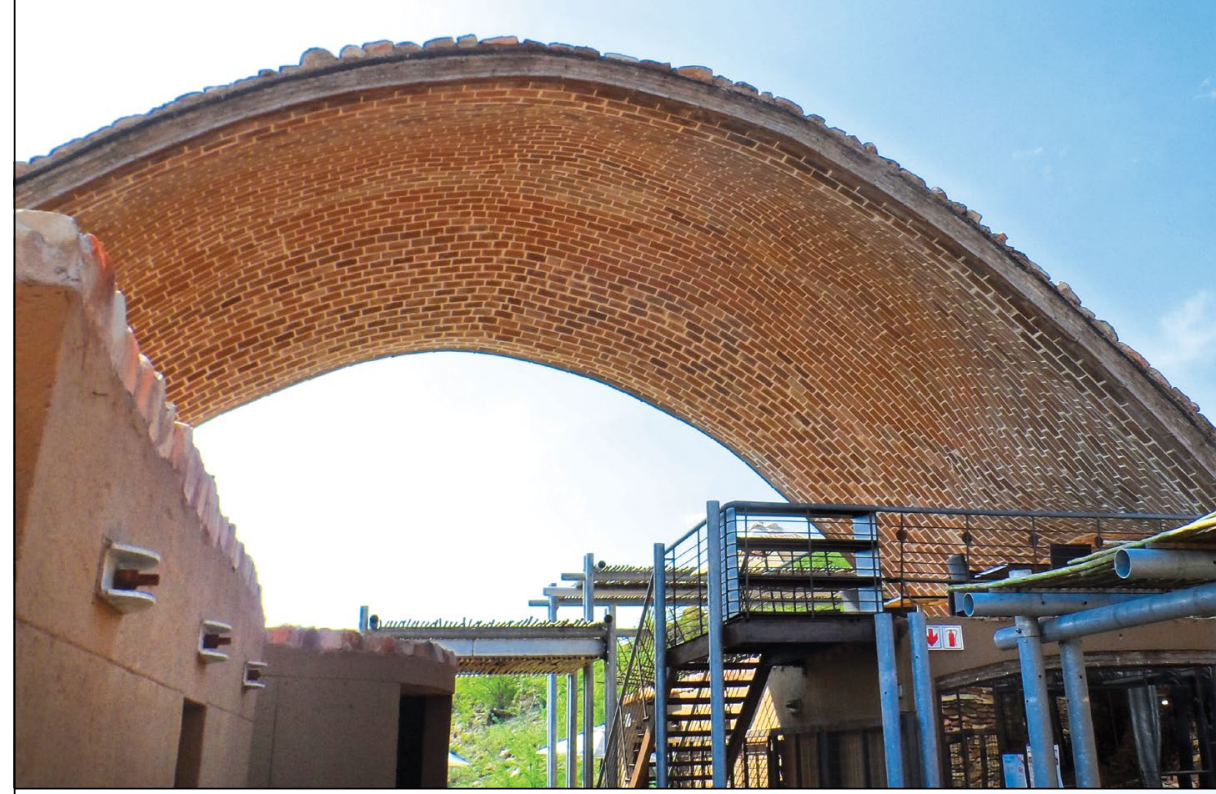

(c)

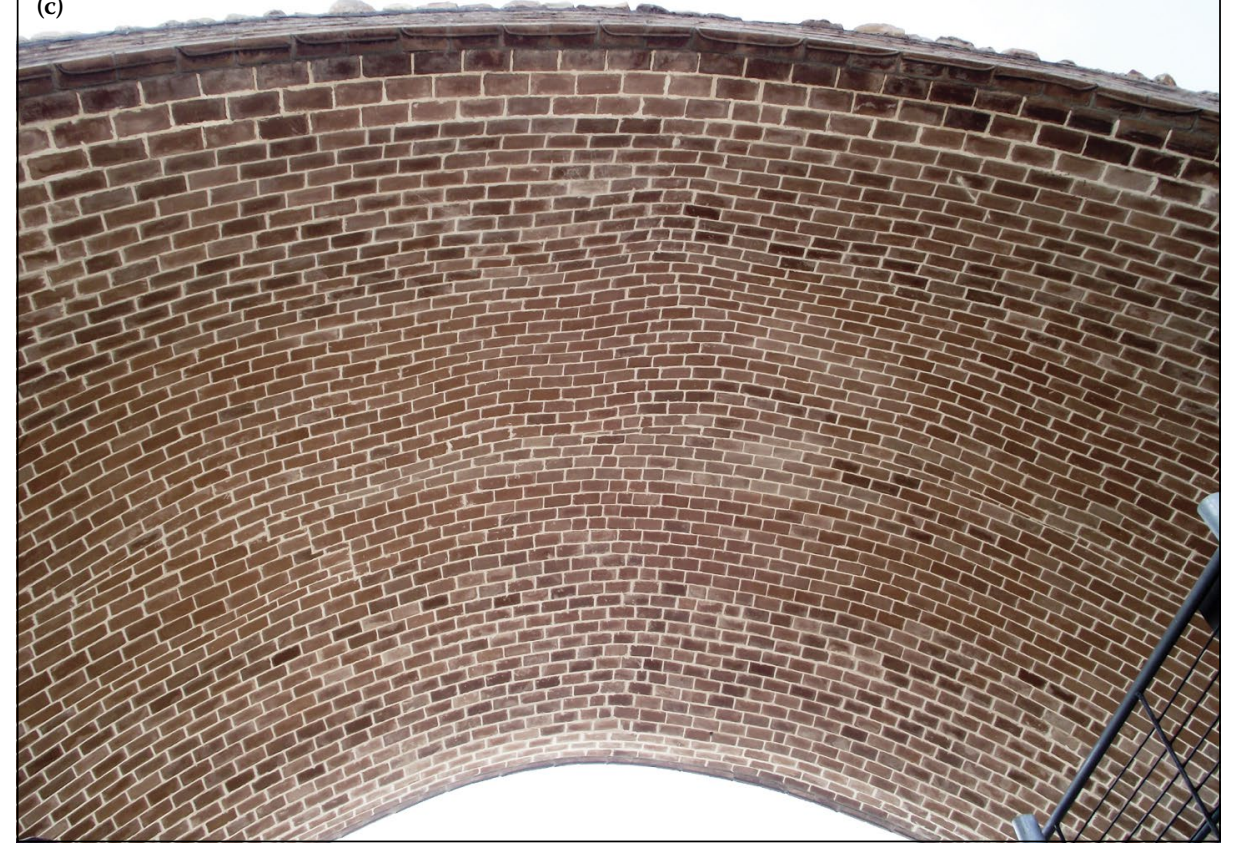

Figure 22 Examples of construction issues in the Mapungubwe shells 
repeatedly in each of the shell forms, which prompted the proposal of three fundamental lessons that can be applied to mitigate the observed cracking in unreinforced masonry shell structures:

- First lesson: Lips and eyebrows are redundant elements of the shell and should be avoided. Incompatibilities and the disparity of stresses between the lips and the catenary dome cause cracking along the interface.

- Second lesson: Shells should be unrestrained against expansion and contraction. This would require that windows, suspended slabs and walls are constructed independently and allow free movement of the shell. The upper region of the shell is more susceptible to cracking, where compressive loads due to self-weight are typically the lowest.

- Third lesson: Openings at the base of shells must be geometrically correct and should ideally be a catenary arch to match the flow pattern of compressive stresses. The inherent weakness of earthen materials necessitates that the shape of the opening is of the correct proportions to prevent a tension zone, which may result in cracking.

\section{REFERENCES}

Allen, E \& Zalewski, W 2010. Form and Forces. Designing Efficient, Expressive Structures. Hoboken, NJ: Wiley.

Farshad, M 1977. On the shape of momentless tensionless masonry domes. Building and Environment, 12(2): 81-89.

Heyman, J 1995. The Stone Skeleton: Structural Engineering of Masonry Architecture, Cambridge: Cambridge University Press.

Kurrer, K 2008. The History of the Theory of Structures: From Arch Analysis to Computational Mechanics. Berlin: Ernst and Sohn.
LISA Finite Element Analysis V.7.6. Sonnenhof Holdings, Ontario, Canada. Available at: http://www.lisafea.com

Mapungubwe Interpretation Centre 2009. World Building of the Year Award, Barcelona, Spain. Available at: http://www.worldbuildingdirectory. com/project.cfm?id=1634

Milkovich, A K 1992.Guastavino tile construction: An analysis of modern cohesive construction techniques. MS thesis, Philadelphia, PA: University of Pennsylvania.

O’Dwyer, D 1999. Funicular analysis of masonry vaults. Computers and Structures, 73(1-5): 187-197.

Ramage, M H, Ochsendorf, J, Rich, P, Bellamy, J K \& Block, P 2010. Design and Construction of the Mapungubwe National Park Interpretive Centre, South Africa. ATDF Journal, 7(1-2): 14-23.

Ramm, E \& Mehlhorn, G 1991. On shape finding methods and ultimate load analysis of reinforced concrete shells. Engineering Structures, 13(2), $178-198$. 